\title{
Prevalence of Astigmatism in Patients Undergoing Cataract Surgery at a Tertiary Care Center in North India
}

This article was published in the following Dove Press journal: Clinical Ophthalmology

\author{
Anuj Sharma (iD \\ Sonia Phulke \\ Anugya Agrawal \\ Isha Kapoor \\ Rakesh Kumar Bansal \\ Department of Ophthalmology, \\ Government Medical College and \\ Hospital (GMCH-32), Sector 32, \\ Chandigarh, 160030, India
}

Correspondence: Sonia Phulke Department of Ophthalmology, Government Medical College and Hospital (GMCH-32), Sector 32,

Chandigarh, 160030, India

Tel +9l-987664II 40

Email soniavaidya2010@yahoo.com

\begin{abstract}
Aim: To assess the demography, magnitude, and type of corneal astigmatism in patients undergoing cataract surgery in North India.

Methods: It is a clinic-based, cross-sectional, observational study. Keratometric values and demographic data were collected for eligible patients who had undergone phacoemulsification at a tertiary eye care center between January 2010 and December 2017, using a non contact, optical low coherence reflectometry (OLCR).

Results: A total of 3597 eyes were recruited for the study. There were 1810 (50.3\%) females and 1787 (49.7\%) males. The mean age was 59.121 \pm 15.19 (range 5-100 years). A total of 3559 eyes were qualified for astigmatism analysis. The mean corneal astigmatism among all patients was $1.17 \pm 1.15 \mathrm{D}$ (range $0-12.5 \mathrm{D}$ ). There was no astigmatism in 99 eyes $(2.78 \%$ ), with-the-rule (WTR) in 1062 eyes (29.83\%), against-the-rule (ATR) in 1843 eyes $(51.72 \%)$ and oblique astigmatism (OA) in 555 eyes $(15.59 \%)$. The tendency of a gradual change from with the rule (WTR) to against the rule (ATR) astigmatism was noted as the age advanced. Conclusion: In the present study around $56.69 \%$ of eyes had corneal astigmatism of $<1.0 \mathrm{D}$ that can be managed by simple cost-effective keratorefractive procedures especially in developing countries. However, our $40.49 \%$ patients had $>1.0 \mathrm{D}$ of corneal astigmatism, which may benefit by toric intraocular lenses.
\end{abstract}

Keywords: corneal astigmatism, cataract, phacoemulsification

\section{Introduction}

Corneal astigmatism in patients with cataract is a significant concern which affects the visual function, vision-related quality of life and leads to increased out-ofpocket expenses. The prevalence of pre-existing anterior corneal astigmatism of $>1.00$ diopter (D), $>1.5 \mathrm{D}$ and $>2.00 \mathrm{D}$ has been reported to range from 32.5-$45.5 \%, 21.0-26.20 \%$ and $8 \%$, respectively, in patients with cataract. ${ }^{1-10}$ The measurement of corneal astigmatism by manual or automated keratometer takes into account several assumptions, which can lead to compromised readings and an unsatisfied post-operative outcome. Instruments based on the principle of optical low coherence reflectometry (OLCR) permit definite measurement of ocular biometric values and have proven more precise than previous conventional techniques. $^{11,12}$

A promising intervention for its management in cataract and intraocular lens (IOL) implant surgery is "Refractive cataract surgery", which refers to the uncomplicated removal of cataract while minimizing postoperative spectacle dependence. 
Correction of corneal astigmatism during phacoemulsification yield better postoperative vision along with decreasing spectacle dependence and is beneficial from economic and cosmetic point of view. ${ }^{13}$

The present study is an assessment of demographics and distribution of corneal astigmatism in the study participants undergoing cataract surgery in a tertiary eye care center in North India by OLCR. The study aimed to estimate the magnitude and type of astigmatism in patients undergoing phacoemulsification.

\section{Patients and Methods}

This study was carried out in the Department of Ophthalmology, Government Medical College and Hospital, Chandigarh, a tertiary-care referral teaching hospital in North India from January 2010 to December 2017. The study was approved by Institutional Ethics Committee, Government Medical College and Hospital (GMCH), Chandigarh. As the study is retrospective and does not include any identifiable parameters of the patient information, patient consent to review their medical records by the investigators was waived off by Institutional Ethics Committee, GMCH, Chandigarh. During the study, patient data remained confidential in compliance with HIPAA and adhered to the Declaration of Helsinki.

Optical biometry and demographic records were screened for all patients who had undergone phacoemulsification in the department.

All the patients with cataract aged 5 years and older were included. We excluded patients with presence of any corneal disease or ocular surface disorders, ocular inflammation or trauma, severe systemic disease, and history of previous corneal or intraocular surgery.

The keratometric values were calculated by using OLCR with an infrared diode laser at a $950 \mathrm{~nm}$ wavelength (LensStar LS9000, Haag-Streit, Switzerland). As per the manufacturer's guidelines, the device measures the corneal radii in steep and flat axis by analyzing a pattern of 32 projected light reflections.

Two rings, with sixteen measuring points on each eye are arranged with an outer diameter of $2.3 \mathrm{~mm}$ and inner diameter of $1.65 \mathrm{~mm}$. The value displayed (flat/steep radius) corresponds to the radii of an ellipsoid that fits into the array of points. At least 5 measurements were taken for each eye and the mean was calculated and taken for the study purpose.

Corneal astigmatism was categorized as with the rule (WTR) when steeper meridian lies between $60-120^{\circ}$, against the rule (ATR) when the steeper meridian lies between $0-30^{\circ} / 150-180^{\circ}$ and, oblique, when it is not ATR/WTR.

When the amount of corneal astigmatism (difference between steep and flat axis) was zero, it was defined as no astigmatism.

For statistical purposes, the participants were stratified into five groups based on their age (in years) as- $<20,21-40$, $41-60,61-80,>80$ years. The medical records obtained were tabulated using Microsoft Excel and were statistically analyzed using SPSS 22.0. (SPSS, Inc., Chicago, IL, USA). Descriptive statistics were used for quantitative variables and expressed as mean \pm standard deviation.

Post hoc analysis was done for multiple comparisons in normally distributed data between different age groups. Kruskal-Wallis test, a non-parametric test was done for the comparison of variance for nonnormally distributed data among different age group. A $p$ value $<0.05$ was considered statistically significant.

\section{Results}

Total 3597 eyes were assessed and among them 3559 eyes were found to be eligible for analysis. The demographics profile of the final study population is listed in Table 1.

The age of the patients ranged from 5 to 100 years, but since the prevalence of visually significant cataract increases with age, patients aged above 60 years contributed to more than half the study population. Figure 1 and Table 2 show the mean corneal astigmatism values for the different age groups. Astigmatism was WTR in 1062 eyes (29.83), ATR in 1843 (51.7\%) eyes, and oblique in 555

Table I Patient Demographic, Corneal Astigmatism and Keratometric Values

\begin{tabular}{|l|c|}
\hline Characteristics & Value \\
\hline Total Number of Eyes (n) & 3559 \\
\hline Sex $n(\%)$ & \\
Male & $1787(49.7 \%)$ \\
Female & $1810(50.3 \%)$ \\
\hline Age (years) & \\
Mean \pm SD & $59.121 \pm 15.19$ \\
Range & $5-100$ \\
\hline Corneal Astigmatism (D) & \\
Mean $\pm S D$ & $1.17 \pm 1.15$ \\
Range (D) & $0-12.5 \mathrm{D}$ \\
Mean $\mathrm{K}_{\mathrm{I}}(\mathrm{D})$ & $43.24 \pm 1.78$ \\
Mean $\mathrm{K}_{2}(\mathrm{D})$ & $44.41 \pm 1.54$ \\
\hline
\end{tabular}

Abbreviations: $K_{1}$, flat keratometry; $K_{2}$, steep keratometry; $D$, diopters. 


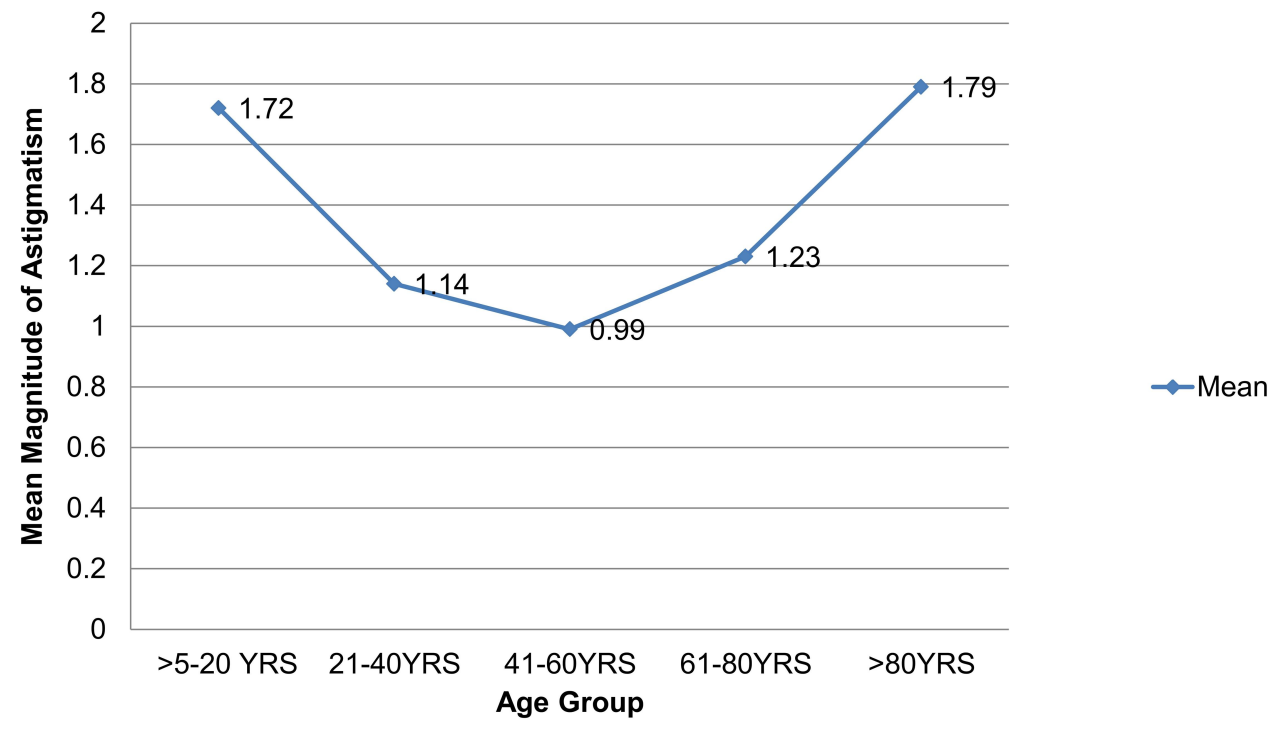

Figure I Mean corneal astigmatism (in diopters) and age (in years).

$(15.59 \%)$ eyes. Incidence of astigmatism decreased from 5 years till $41-60$ years, and after 60 years it increased with age. WTR astigmatism was noted to be $56.93 \%$ in $>20-40$ years age group and ATR astigmatism steadily increased to $71.42 \%$ in $>80$ years age group. This change in trend from WTR to ATR was noted in patients aged 40 years and above (Figure 2). The distribution of the amount of astigmatism for the different age groups is depicted in Table 3 and in Figure 3A-E. On correlating the type of astigmatism with age, it was seen that with advancing age, there was a tendency for an increase in ATR astigmatism, and a decrease in WTR astigmatism (Figure 2), while oblique astigmatism did not show any trend with age. In 99 eyes, of which 34 (34.30\%) were females and 65 (65.65\%) were males, there was no astigmatism.

\section{Discussion}

The quality of vision in a pseudophakic eye is greatly affected by the degree of astigmatism. Addressing astigmatism during cataract surgery has become increasingly

Table 2 The Mean Corneal Astigmatism in the Various Age Groups

\begin{tabular}{|l|c|c|}
\hline $\begin{array}{l}\text { Age Group } \\
\text { (Years) }\end{array}$ & $\begin{array}{c}\text { Number of Eyes } \\
\text { n (\%) }\end{array}$ & $\begin{array}{c}\text { Mean Astigmatism } \\
\text { Mean+SD }\end{array}$ \\
\hline$>5-20$ & $138(3.8)$ & $1.721 \pm 1.4149$ \\
$21-40$ & $219(6.15)$ & $1.139 \pm 1.3141$ \\
$4 I-60$ & $1214(34.1)$ & $0.986 \pm 0.995$ \\
$61-80$ & $1902(53.4)$ & $1.228 \pm 1.152$ \\
$>80$ & $86(2.41)$ & $1.794 \pm 1.722$ \\
\hline
\end{tabular}

important in recent times with the demand for spectacle independence from patients. The current study reports that $40.49 \%$ of the patients had astigmatism of more than 1.00 $\mathrm{D}$ and were thus the candidates for astigmatic correction during cataract surgery. Our data was in accordance with Prasher $\mathrm{P}$ et al and Curragh DS et al, who reported a prevalence of $40.6 \%$ and $41.3 \%$, respectively, ${ }^{3,4}$ whereas it varied from Joshi RS et al, Ferrer-Blasco $\mathrm{T}$ et al and $\mathrm{Oh}$ EH et al, who reported a prevalence of $32.5 \%, 34.8 \%$ and $35 \%$ of more than $1.00 \mathrm{D}$ corneal astigmatism in their respective studies. ${ }^{1,2,14}$ The mean age of our study population is $59.121 \pm 15.19$ years which coincides with the observation of Prasher $\mathrm{P}$ et al and Isyaku et al. ${ }^{3,15}$

The mean corneal astigmatism in the study population was noted to be $1.17 \pm 1.15 \mathrm{D}$ (Range $0-12.5 \mathrm{D}$ ), which is slightly higher than the previously published studies. ${ }^{1,16-18}$

The difference could be attributed to eligibility criteria, age, racial factor, and methods of keratometry measurements. The mean magnitude of astigmatism was noted to decrease to a minimal in the age group of 40-60 years after which it was noted to increase progressively with age $(\mathrm{p}<0.001)$. A similar progressive increase in mean astigmatism with age has also been reported in the available literature. ${ }^{17-19}$

The number of eyes with neutral astigmatism was noted to be of the same order as that noted in the study of Isyaku et al. ${ }^{15}$ Regarding gender distribution, the number of females outnumbered the males which are similar from reports of other studies on this subject. ${ }^{20,21}$

The shift of astigmatism was noted significantly as the age advanced $(\mathrm{p}<0.001)$. There was a gradual shift from 


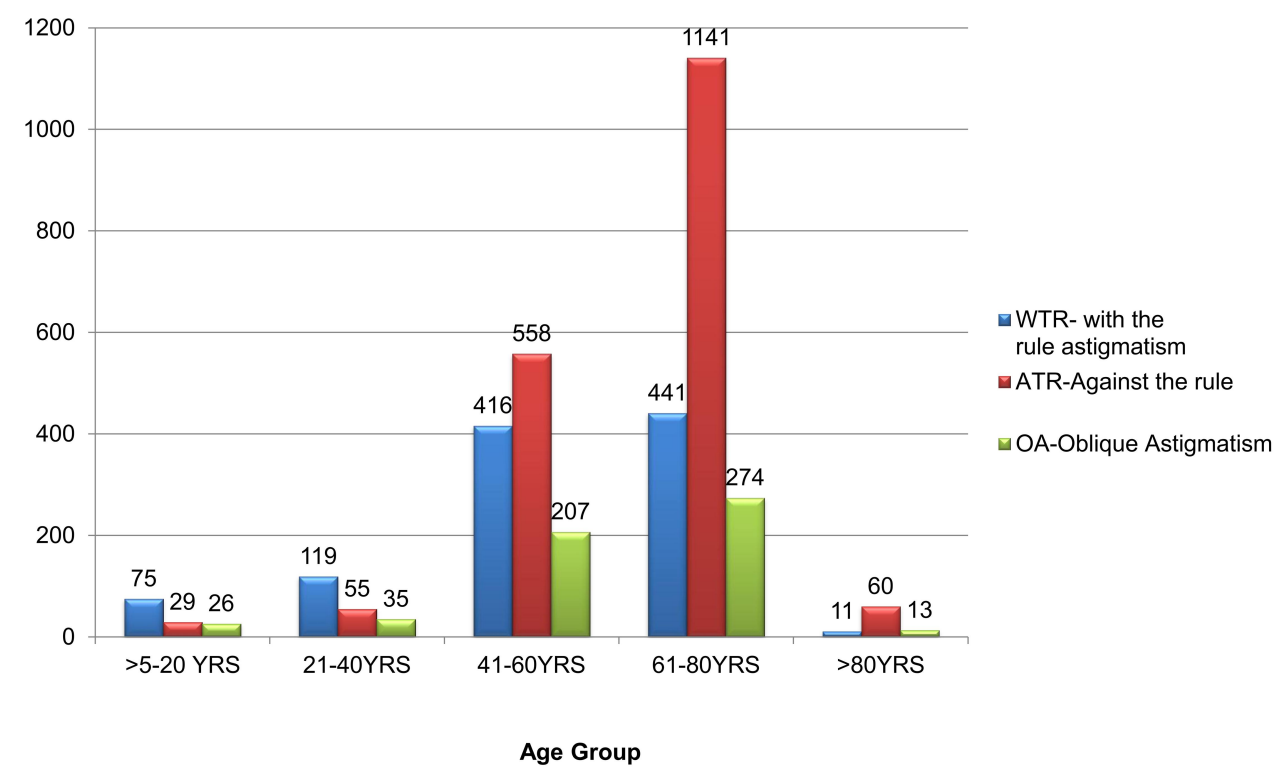

Figure 2 Types of astigmatism in various age groups.

WTR astigmatism to ATR astigmatism with an increase in age. This change was noted after 40 years of age. Oblique astigmatism was not noted to vary with age. Similar results have also been reported in previous studies on this subject. ${ }^{6,10,16}$

In the present study, ATR astigmatism was noted to be the most prevalent astigmatism contributing to $51.7 \%$ of the cases, which coincides with Joshi RS et al. ${ }^{1}$ This can be attributed to the mean age of the population 59.121 \pm 15.19 years since cataract is mainly a disease of the elderly. However, Bernardo et $\mathrm{al}^{22}$ and Hoffman and Hutz $^{10}$ have reported a higher prevalence of WTR astigmatism (44\% and $46.8 \%$, respectively) as compared to ATR astigmatism.

Table 3 Magnitude of Astigmatism in the Study Population

\begin{tabular}{|l|c|}
\hline Magnitude of Astigmatism (D) & Number of Eyes n (\%) \\
\hline Zero & $99(2.78 \%)$ \\
$<0.50$ & $665(18.68 \%)$ \\
$<0.50-1.00$ & $1353(38.01 \%)$ \\
$1.01-1.50$ & $646(18.15 \%)$ \\
$1.51-2.00$ & $329(9.24 \%)$ \\
$2.01-2.50$ & $183(5.14 \%)$ \\
$2.51-3.0$ & $98(2.75 \%)$ \\
$3.01-3.50$ & $63(1.77 \%)$ \\
$3.51-4.0$ & $38(1.06 \%)$ \\
$>4.00$ & $85(2.38 \%)$ \\
\hline
\end{tabular}

Abbreviation: D, diopter.
Various factors such as physiological changes in the corneal curvature as age advances, pressure from eyelids, pressure by intraocular pressure, and of the extraocular muscles have been anticipated to be responsible factors for changes in ATR and WTR with age.

Several techniques have been developed in recent years to combat pre-operative astigmatism during cataract surgery. The approaches include on-axis phacoemulsification, opposite clear corneal incisions, limbal relaxing incisions, toric IOLs, and excimer laser refractive procedures. The choice of the procedure to be performed depends upon the amount of pre-operative corneal astigmatism. ${ }^{23}$ The present study utilized the LensStar LS9000, which is based on the principle of optical low coherence reflectometry, which is a non invasive, non contact optical biometer.

A stepladder approach is recommended with on-axis phacoemulsification and opposite clear corneal incisions being used when the astigmatism is $<1.0 \mathrm{D}$. This present approach can be undertaken in $56.69 \%$ of the cases as seen in our study. However, the surgeon should be competent in changing the phacoemulsification incision to different meridians and must be comfortable operating in those different positions.

Another approach in addressing astigmatism is the use of toric IOLs, which have shown to be clinically useful when the pre-operative astigmatism is greater than 1.50 D. This magnitude of astigmatism was noted in $22.38 \%$ of the patient understudy, who are thus potential candidates for this procedure. Production of a low and cost-effective 


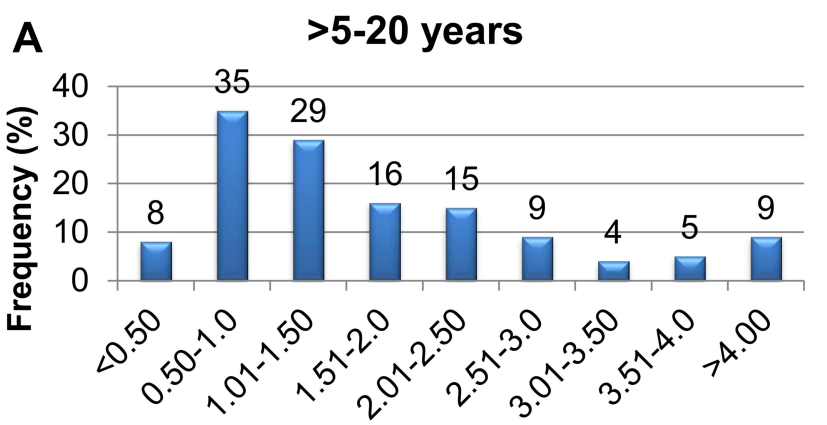

Astigmatism

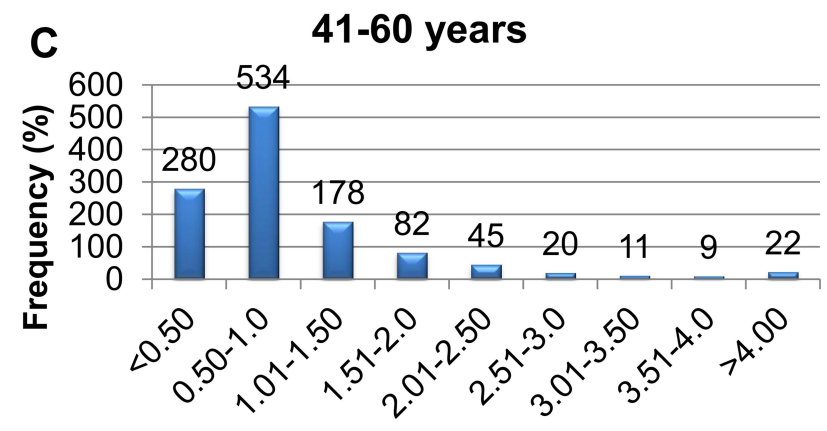

Astigmatism

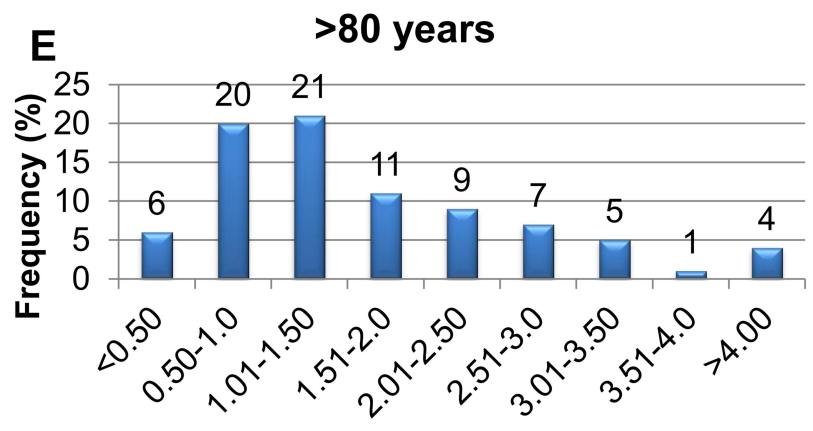

Astigmatism

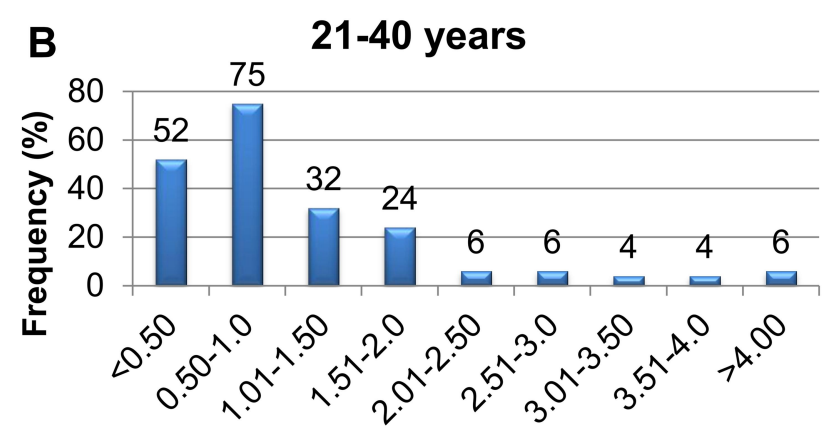

Astigmatism

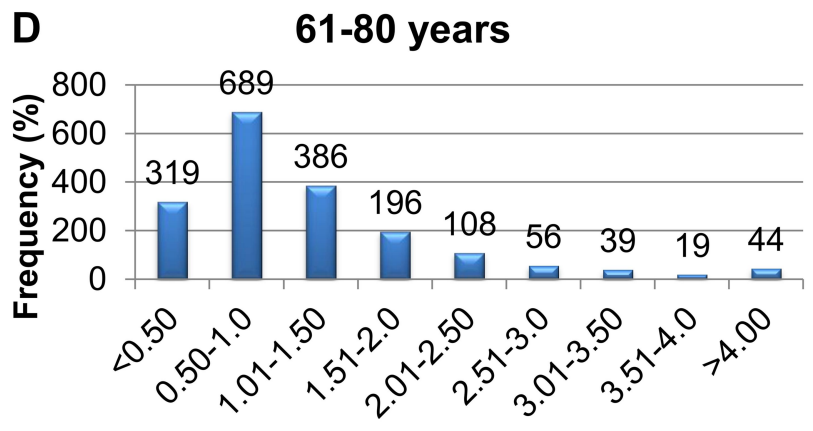

Astigmatism

Figure 3 (A-E) Distribution of corneal astigmatism (in diopters) values for the different age groups.

toric IOL will thus help provide quality vision to a larger section of the Indian population.

The present study is the first study including largest cohort from North India, where astigmatism was calculated by using OLCR. The other previously reported studies in Indian population is done by using autorefractokeratometer and had relatively smaller sample size. ${ }^{1,3,16}$

Our study has few limitations. First, it is a retrospective study, which itself carries the risk of potential inaccuracy in records management, and second, it is a hospital-based study. Future studies with community-based approach would improve the data extrapolation.
To conclude, the present study reveals the prevalence of different types of astigmatism in patients undergoing cataract surgery in a tertiary care center in North India, and recorded more than $1.0 \mathrm{D}$ of astigmatism in $40.49 \%$ of eyes, which should be addressed during cataract surgery using the approaches as discussed above. Corneal astigmatism was found to increase with age after 40 years and a shift from WTR to ATR astigmatism was noted with advancing age. With the improvement in the quality of healthcare and better age expectancy more number of patients would require quality vision following cataract surgery, which can only be achieved if pre-operative astigmatism correction is taken into consideration. 


\section{Disclosure}

The authors report no conflicts of interest in this work.

\section{References}

1. Joshi RS, Jadhav SA. Frequency of corneal astigmatism in patients presenting for senile cataract surgery at a teaching hospital in Indian rural population. Asia Pac J Ophthalmol. 2020;9(2):126-129. doi:10.1097/APO.0000000000000262

2. Ferrer-Blasco T, Montes-Mico R, Peixoto-de-Matos SC, GonzalezMeijome JM, Cervino A. Prevalence of corneal astigmatism before cataract surgery. $J$ Cataract Refract Surg. 2009;35(1):70-75. doi:10.1016/j.jcrs.2008.09.027

3. Prasher P, Sandhu JS. Prevalence of corneal astigmatism before cataract surgery in Indian population. Int Ophthalmol. 2017;37 (3):683-689. doi:10.1007/s10792-016-0327-z

4. Curragh DS, Hassett P. Prevalence of corneal astigmatism in an NHS cataract surgery practice in Northern Ireland.. Ulster Med J. 2017;86(1):25-27.

5. Yu J-G, Zhong J, Mei Z-M, Zhao F, Tao N, Xiang Y. Evaluation of biometry and corneal astigmatism in cataract surgery patients from Central China. BMC Ophthalmol. 2017;17(1):56-62. doi:10.1186/ s12886-017-0450-2

6. Collier Wakefield O, Annoh R, Nanavaty MA. Relationship between age, corneal astigmatism, and ocular dimensions with reference to astigmatism in eyes undergoing routine cataract surgery. Eye. 2016;30(4):562-569. doi:10.1038/eye.2015.274

7. Natung T, Shullai W, Nongrum B, Thangkhiew L, Baruah $P$, Phiamphu ML. Ocular biometry characteristics and corneal astigmatisms in cataract surgery candidates at a tertiary care center in North-East India. Indian J Ophthalmol. 2019;67(9):1417-1423. doi:10.4103/ijo.IJO_1353_18

8. Day AC, Dhariwal M, Keith MS, et al. Distribution of preoperative and postoperative astigmatism in a large population of patients undergoing cataract surgery in the UK. Br J Ophthalmol. 2019;103 (7):993-1000. doi:10.1136/bjophthalmol-2018-312025

9. Mohammadi M, Naderan M, Pahlevani R, Jahanrad A. Prevalence of corneal astigmatism before cataract surgery. Int Ophthalmol. 2016;36 (6):807-817. doi:10.1007/s10792-016-0201-z

10. Hoffmann PC, Hutz WW. Analysis of biometry and prevalence data for corneal astigmatism in 23,239 eyes. J Cataract Refract Surg. 2010;36(9):1479-1485. doi:10.1016/j.jcrs.2010.02.025

11. Rohrer K, Frueh BE, Wälti R, Clemetson IA, Tappeiner C, Goldblum D. Comparison and evaluation of ocular biometry using a new noncontact optical low-coherence reflectometer. Ophthalmology. 2009;116(11):2087-2092. doi:10.1016/j.ophtha.20 09.04.019
12. Laurendeau C, Lafuma A, Berdeaux G. Modelling lifetime cost consequences of toric compared with standard IOLs in cataract surgery of astigmatic patients in four European countries. J Med Econ. 2009;12(3):230-237. doi:10.3111/13696990903257439

13. Salouti R, Nowroozzadeh MH, Zamani M, Ghoreyshi M, Salouti R. Comparison of the ultrasonographic method with 2 partial coherence interferometry methods for intraocular lens power calculation. Optometry. 2011;82(3):140-147. doi:10.1016/j.optm.2010.07.025

14. Oh E-H, Kim H, Lee HS, Hwang K-Y, Joo C-K. Analysis of anterior corneal astigmatism before cataract surgery using power vector analysis in eyes of Korean patients. J Cataract Refract Surg. 2015;41 (6):1256-1263. doi:10.1016/j.jcrs.2014.09.043

15. Isyaku M, Ali SA, Hassan S. Preoperative corneal astigmatism among adult patients with cataract in Northern Nigeria. Indian J Ophthalmol. 2014;62(11):1094-1095. doi:10.4103/0301-4738.146751

16. Moulick PS, Kalra D, Sati A, Gupta S, Khan MA, Singh A. Prevalence of corneal astigmatism before cataract surgery in Western Indian Population. Med J Armed Forces India. 2018;74 (1):18-21. doi:10.1016/j.mjafi.2017.02.003

17. Raúl LE, Milena OA, Alberto VL, Emilio CA. Corneal astigmatism in cataract surgery candidates. Rev Bras Oftalmol. 2018;77 (5):272-277.

18. Yuan X, Song H, Peng G, Hua X, Tang X. Prevalence of corneal astigmatism in patients before cataract surgery in northern China. J Ophthalmol. 2014;2014:536412. doi:10.1155/2014/536412

19. Khabazkhoob M, Norouzirad R, Rezvan F, Yekta A, Hashemi H, Hashemi M. The prevalence of astigmatism and its determinants in a rural population of Iran: the "Nooravaran Salamat" mobile eye clinic experience. Middle East Afr J Ophthalmol. 2014;21 (2):175-181. doi:10.4103/0974-9233.129772

20. Chen W, Zuo C, Chen C, et al. Prevalence of corneal astigmatism before cataract surgery in Chinese patients. J Cataract Refract Surg. 2013;39(2):188-192. doi:10.1016/j.jcrs.2012.08.060

21. Guan Z, Yuan F, Yuan Y-Z, Niu W-R. Analysis of corneal astigmatism in cataract surgery candidates at a teaching hospital in Shanghai, China. J Cataract Refract Surg. 2012;38(11):1970-1977. doi:10.1016/j.jcrs.2012.07.025

22. De Bernardo M, Zeppa L, Cennamo M, Iaccarino S, Zeppa L, Rosa N. Prevalence of corneal astigmatism before cataract surgery in Caucasian patients. Eur J Ophthalmol. 2014;24(4):494-500. doi:10.5301/ejo.5000415

23. Freitas GO, Boteo JE, Carvalho MJ, Pinto RM. Treatment of astigmatism during phacoemulsification. Arg Bras Oftalmol. 2014;77 (1):40-46.
Clinical Ophthalmology

\section{Publish your work in this journal}

Clinical Ophthalmology is an international, peer-reviewed journal covering all subspecialties within ophthalmology. Key topics include: Optometry; Visual science; Pharmacology and drug therapy in eye diseases; Basic Sciences; Primary and Secondary eye care; Patient Safety and Quality of Care Improvements. This journal is indexed on PubMed

\section{Dovepress}

Central and CAS, and is the official journal of The Society of Clinical Ophthalmology (SCO). The manuscript management system is completely online and includes a very quick and fair peer-review system, which is all easy to use. Visit http://www.dovepress.com/ testimonials.php to read real quotes from published authors. 